\begin{tabular}{|l|l|}
\hline Problemas y perspectivas de la teoría de la dependencia (1974) & Titulo \\
\hline Cueva, Agustín - Autor/a & Autor(es) \\
\hline Entre la ira y la esperanza y otros ensayos de crítica latinoamericana & En: \\
\hline Buenos Aires y Bogotá & Lugar \\
\hline $\begin{array}{l}\text { CLACSO, Consejo Latinoamericano de Ciencias Sociales } \\
\text { Siglo del Hombre Editores }\end{array}$ & Editorial/Editor \\
\hline 2008 & Fecha \\
\hline $\begin{array}{l}\text { Revolución Cubana; Lucha de Clases; Capitalismo; Izquierda; Marxismo; Teoría de la } \\
\text { Dependencia; Sociología Política; Desarrollo Económico y Social; Dependencia } \\
\text { Económica; América Latina; }\end{array}$ & Temas \\
\hline Capítulo de Libro & Tipo de documento \\
\hline http://bibliotecavirtual.clacso.org.ar/clacso/se/20100830114245/05problemas.pdf & URL \\
\hline $\begin{array}{l}\text { Reconocimiento-No comercial-Sin obras derivadas 2.0 Genérica } \\
\text { http://creativecommons.org/licenses/by-nc-nd/2.0/deed.es }\end{array}$ & Licencia \\
\hline
\end{tabular}

Segui buscando en la Red de Bibliotecas Virtuales de CLACSO

http://biblioteca.clacso.edu.ar

Consejo Latinoamericano de Ciencias Sociales (CLACSO)

Conselho Latino-americano de Ciências Sociais (CLACSO)

Latin American Council of Social Sciences (CLACSO)

www.clacso.edu.ar
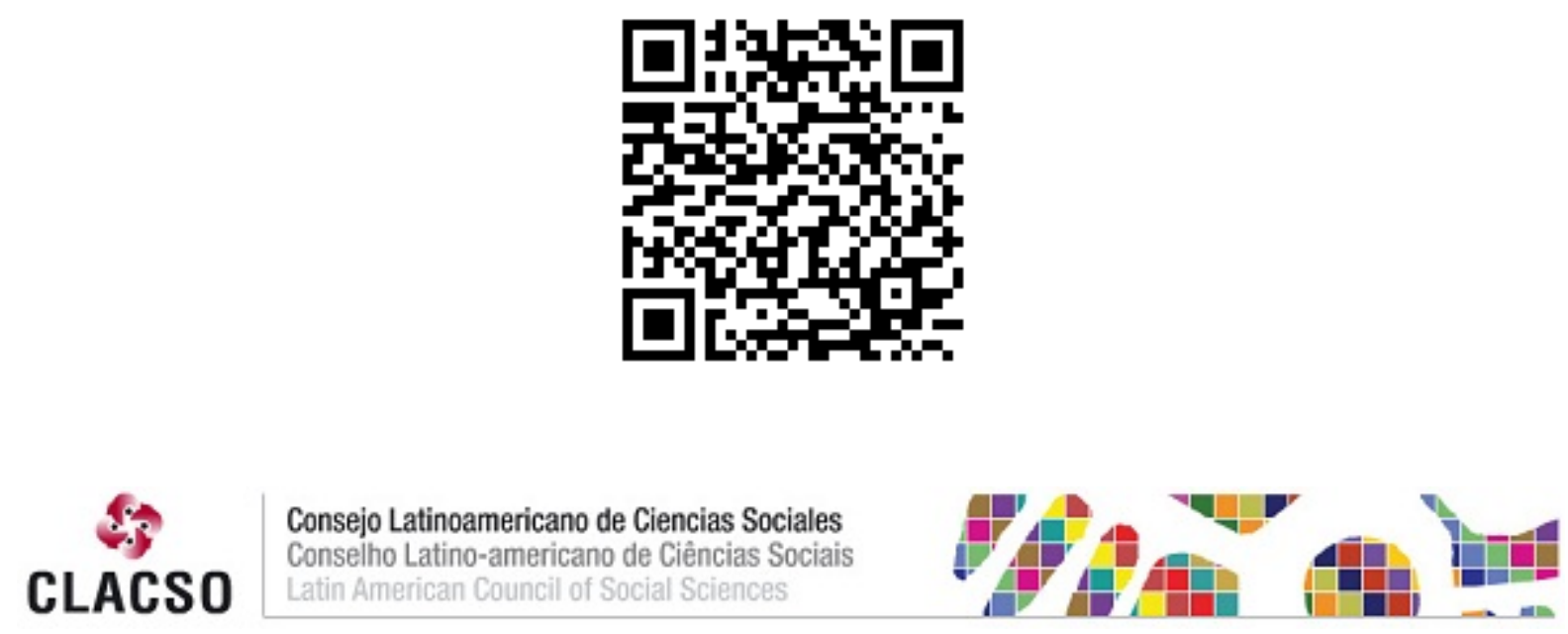
Cueva, Agustín. Problemas y perspectivas de la teoría de la dependencia (1974). En publicación: Entre la ira y la esperanza y otros ensayos de crítica latinoamericana. Fundamentos conceptuales Agustín Cueva.

Antología y presentación Alejandro Moreano. Bogotá: Siglo del Hombre - CLACSO, 2008. ISBN 978-958-665-108-0

Disponible en: http://bibliotecavirtual.clacso.org.ar/ar/libros/secret/critico/cueva/05problemas.pdf

Red de Bibliotecas Virtuales de Ciencias Sociales de América Latina y el Caribe de la Red CLACSO http://www.clacso.org.ar/biblioteca 


\section{PROBLEMAS Y PERSPECTIVAS DE LA TEORÍA DE LA DEPENDENCIA ${ }^{1}$}

La teoría de la dependencia, al menos en su vertiente de izquier$\mathrm{da}$, que es la que aquí nos interesa analizar, nace marcada por una doble perspectiva sin la cual es imposible comprender sus principales supuestos y su tortuoso desarrollo. Por una parte, surge como una violenta impugnación de la sociología burguesa y sus interpretaciones del proceso histórico latinoamericano, oponiéndose a teorías como la del dualismo estructural, la del funcionalismo en todas sus variantes $y$, por supuesto, a las corrientes desarrollistas. Con esto cumple una positiva función crítica, sin la cual sería imposible siquiera imaginar la orientación actual de la sociología universitaria en América Latina. Por otra parte, emerge en conflicto con lo que a partir de cierto momento dará en llamarse el "marxismo tradicional".

Ahora bien, toda la paradoja y gran parte de la originalidad de la teoría de la dependencia estriba, no obstante, en una suerte de cruzamientos de perspectivas que determina que, mientras por un lado se critica a las corrientes burguesas desde un punto de vista cercano al marxista, por otro se critique al marxismo-leninismo

1 Extraído de Agustín Cueva, Teoría social y procesos políticos en América Latina, México, EDICOL, $1^{a}$ ed., 1979, pp. 15-39. 
desde una óptica harto impregnada de desarrollismo y de concepciones provenientes de las ciencias sociales burguesas.

El debate sobre feudalismo y capitalismo en América Latina, que derramó mucha tinta y sembró no poca confusión teórica, es, sin duda, el ejemplo más claro, aunque no el único, de lo que venimos diciendo. Debate situado aparentemente en el seno del marxismo, es el que Gunder Frank y Luis Vitale ${ }^{2}$ sostuvieron con la "izquierda tradicional". Tiene éste, empero, la particularidad de que los autores se formulan tesis que sólo se vuelven comprensibles a condición de abandonar la teoría marxista.

En efecto, y siempre que uno haga caso omiso de El capital y se ubique de lleno en la óptica de la economía y la historiografía no marxistas, las aseveraciones de Frank y Vitale se tornan límpidas e irrefutables. Definido el capitalismo como economía monetaria y el feudalismo como economía de trueque o, en el mejor de los casos, como economía "abierta" y economía "cerrada", respectivamente, pocas dudas caben de que el capitalismo se instaló plena y profundamente en América Latina no sólo desde su cuna sino desde su concepción, como llegó a decirse. Para demostrarlo, ni siquiera era menester realizar nuevas investigaciones históricas - y en efecto, nadie se tomó el trabajo de hacerlas-; bastaba retomar los materiales proporcionados por la historiografía existente y demostrar que en el período colonial hubo moneda y comercio. Se podía seguir, en suma, aunque no sin caricaturizarlo, un razonamiento análogo al que permite a Pirenne afirmar la existencia de capitalismo en la Edad Media, a partir del siglo XII por lo menos. ${ }^{3}$

Todo esto, envuelto en una especie de mesianismo cuya lógica política resulta, además, imposible de entender; a menos de to-

2 Luis Vitale nunca formuló, desde luego, una teoría de la dependencia. Pero si trabajos suyos, como el titulado América Latina: ¿feudal o capitalista?, alcanzaron tanta difusión, es porque se inscribían dentro de una perspectiva teórica que ya empezaba a pensar nuestra problemática en términos izquierdistas pero que visiblemente se alejan de los del marxismo-leninismo.

3 Véase, por ejemplo, su Historia económica y social de la Edad Media, México, Fondo de Cultura Económica, 1969, pp. 119 y ss. 
marla como lo que en realidad fue: una ilusión de intelectuales. Las que aparecían entonces como nuevas líneas revolucionarias en América Latina, esto es, el castrismo y el maoísmo, ${ }^{4}$ se habían constituido desde luego con mucha anterioridad al "descubrimiento" del carácter no feudal de la Colonia; y, en cuanto a la táctica de frentes populares que se quería impugnar, era obvio que no iba a derrumbarse con el solo retumbar de estas nuevas trompetas de Jericó. El frente que se formó en Francia en 1936, por ejemplo, no necesitó hablar de feudalismo para sustentarse.

Sea de ello lo que fuere, lo que importa destacar aquí es esta primera gran paradoja que envolverá a la teoría de la dependencia "desde su cuna": la de constituirse como un "neomarxismo" al margen de Marx. Hecho que pesará mucho en toda la orientación de la sociología latinoamericana contemporánea y terminará por ubicar a dicha teoría en el callejón sin salida en el que actualmente se encuentra.

Esta situación ambigua debilitará incluso las críticas hechas a las teorías burguesas del desarrollo y el subdesarrollo, en la medida en que sus impugnadores permanecen, de una u otra manera, prisioneros de ellas. Es lo que ocurre con Gunder Frank, por ejemplo, quien en su ensayo La sociología del desarrollo y el subdesarrollo de la sociología, por lo demás muy meritorio, entabla una descomunal batalla con los discípulos de Parsons, destinada a saber dónde existen pautas más "universales" de comportamiento, si en los países desarrollados o en los subdesarrollados; ${ }^{5}$ embarcándose en una polémica barroca de la que ni siquiera es seguro que resulte vencedor. Después de todo, la mistificación de los parsonianos no radica en el hecho de encontrar en los paí-

4 Lo que en determinado momento se denominó “castrismo”, evolucionó en Cuba hacia un sólido marxismo-leninismo; en los demás países de América Latina el proceso fue más complejo. En cuanto al maoísmo, se ha convertido en la actualidad en la extrema izquierda del imperialismo. Las citas que aquí se hacen de trabajos de Mao deben tomarse como simples referencias teóricas, que jamás implicaron simpatía alguna por la política de Pekín (nota de 1979).

5 Véase Desarrollo del subdesarrollo, México, Escuela Nacional de Antropología e Historia, 1969, pp. 34 y ss. 
ses subdesarrollados orientaciones de conducta, que en realidad pueden darse en áreas donde el modo de producción capitalista aún no se ha desarrollado suficientemente; sino en sustituir el análisis de las estructuras por el de sus efectos más superficiales y presentar a éstos como las determinaciones últimas del devenir social.

El mismo debate sobre el dualismo estructural, tesis burguesa que en realidad era menester impugnar, parece desembocar a menudo en la simple recreación de un dualismo de signos invertidos, en el que el planteamiento, y por lo tanto los elementos básicos del análisis, no cambian, sino sólo su papel. En las Siete tesis equivocadas sobre América Latina de Rodolfo Stavenhagen, por ejemplo ${ }^{6}$ los sectores "tradicional" y "moderno" siguen presentes como unidades analíticas fundamentales, con la única diferencia de que ahora ya no es el sector "tradicional" el causante del atraso sino más bien el sector "moderno". Por eso, la misma teoría del colonialismo interno, al menos tal como es presentada en las Siete tesis..., dificulta el análisis de clase en vez de facilitarlo; conduciendo, además, a conclusiones sumamente cuestionables como aquella de la séptima tesis, en donde se formula la inviabilidad de la alianza obrero-campesina en Latinoamérica, aduciendo que "la clase obrera urbana de nuestros países también se beneficia con la situación de colonialismo interno". El propio autor parece haber sentido las limitaciones de este tipo de enfoque, por lo que reformulará posteriormente su tesis del colonialismo interno en términos de combinación de modos de producción, ${ }^{7}$ retomando de esta manera uno de los conceptos centrales del marxismo clásico, que en las Siete tesis... aparecía más bien catalogado como una sofisticada variante del dualismo estructural.

6 Stavenhagen no formula en rigor una teoría de la dependencia y, lo que es más, se aparta del horizonte teórico de ésta en sus trabajos más amplios. Pero las Siete tesis se escriben indudablemente bajo la influencia de los autores dependentistas y constituyen en cierta medida el manifiesto de toda una generación.

7 Véase su intervención en el seminario sobre clases sociales realizado en Oaxaca en 1971, reproducida en Las clases sociales en América Latina, México, Siglo XXI, 1973, pp. 280-281. 
De todas maneras, hay en este trabajo de Stavenhagen, y sobre todo en los de Frank, la presencia de un esquema en el cual la explotación, y por tanto las contradicciones de clases, son reemplazadas por un sistema indeterminado de contradicciones nacionales y regionales que, justamente por su indeterminación, no deja de plantear serios problemas desde un punto de vista estrictamente marxista. A este respecto, antes que preguntarse si el modelo frankiano, por ejemplo, es compatible o no con un análisis de clase, resulta importante constatar que en ensayos como el titulado Chile: el desarrollo del subdesarrollo, la lucha de clases está simplemente ausente, pese a que en dicho país, hasta donde sabemos, la historia no parece ser muy pobre en este aspecto.

Este desplazamiento que convierte a los países y regiones en unidades últimas e irreductibles del análisis, es el que confiere, además, un tinte marcadamente nacionalista a la teoría de la dependencia, y no porque la contradicción entre países dependientes y estados imperialistas no se dé históricamente, cosa que sería absurdo negar, sino porque un inadecuado manejo de la dialéctica impide ubicar el problema en el nivel teórico que le corresponde: esto es, como una contradicción derivada de otra mayor, la de clases, y que sólo en determinadas condiciones puede pasar a ocupar el papel principal. Si no nos equivocamos, el único texto en que se aborda este problema de manera sistemática e inequívoca es Imperialismo y capitalismo de Estado, de Aníbal Quijano; ${ }^{8}$ pero no se olvide que tal escrito data de 1972, cuando ya los cimientos de la teoría de la dependencia están bastante resquebrajados y el propio Quijano se encuentra, a nuestro juicio, más cerca del marxismo a secas que de aquella corriente.

Y no es únicamente en estos puntos, de por sí importantes, que los nuevos modelos de análisis cojean. Antidesarrollista y todo lo que se quiera, la teoría de la dependencia sigue moviéndose, de hecho, dentro del campo problemático impuesto por la corriente desarrollista e incluso atrapada en su perspectiva economicista. Ocurre como si el neomarxismo latinoamericano, al

8 Revista Sociedad y política, No. 1, Lima, junio de 1972, p. 5. 
polemizar con sus adversarios, hubiera olvidado o desconocido la tajante advertencia de Marx en La ideología alemana: "No es sólo en las respuestas, sino en las preguntas mismas, donde ya hay una mistificación".

En efecto, la pregunta que se hicieron los desarrollistas al comenzar la década de los sesenta venía ya cargada de ideología, no sólo porque al indagar cuáles eran los escollos para un "desarrollo económico-social acelerado y armónico" de nuestros países, escamoteaban la cuestión central (explotación de clase) y reducían la problemática a la del simple desarrollo indeterminado de las fuerzas productivas, imponiendo así una perspectiva economicista; sino también porque, de hecho, tal pregunta involucraba la aceptación de que es posible alcanzar un desarrollo de este tipo - equilibrado, armonioso, sin depresiones ni crisis—, bajo el sistema capitalista. Así y todo, la pregunta tenía un sentido y una coherencia, que le eran dados precisamente por la ideología de clase en que se sustentaba. En cambio, ¿qué sentido podría tener para un marxista formularse las mismas preguntas, sin antes desmontar y rehacer toda esta problemática? ¿De qué desarrollo frustrado o frenado se estaba hablando en este caso?

Frank encontró, desde luego, una fórmula mágica, la del "desarrollo del subdesarrollo", que entre otros supuestos implicaba el de la "continuidad en el cambio", que Theotonio dos Santos no tardó en señalar, con razón, como una concepción adialéctica. ${ }^{9}$ En realidad, se trataba de un mito, tal vez no del eterno retorno, pero sí de la eterna identidad, que, en lugar de introducir una dimensión histórica en el análisis, suprimía la historia de una sola plumada. Pero aun así Frank tuvo que recurrir a sutiles acrobacias verbales para apuntalar una teoría en la que la retórica ocupaba visiblemente las lagunas dejadas por la dialéctica:

9 "El capitalismo colonial según André Gunder Frank", en Theotonio dos Santos, Dependencia y cambio social, Cuadernos de Estudios Socioeconómicos, No. 11, Universidad de Chile, CESO, 1970, pp. 151 y ss. 
$\mathrm{Al}$ extender esta vieja tesis sobre las regiones más colonializadas y explotadas, para comprender no sólo Latinoamérica sino Asia y África también; y, al denominarlas "ultrasubdesarrolladas" en mi exposición en Caracas, los compañeros Francisco Mieres y Héctor Silva Michelena objetaron que, conforme a mi "teoría”, el ultrasubdesarrollo debería darse no en aquellas regiones anteriormente más colonizadas, sino en las actualmente más colonizadas, y que, de hecho, según Silva, el país que sufre más ultrasubdesarrollo en América Latina es Venezuela. La objeción teórica me pareció correcta y, también, la evaluación del ultrasubdesarrollo venezolano a causa de la ultraexplotación del boom de exportación de petróleo. Acordamos denominar, muy provisionalmente, este último como un desarrollo "activo" del ultrasubdesarrollo y buscar otra palabra conceptual para el estado "pasivo” del ultrasub (¿o lumpen?) desarrollo de aquellas regiones de exportación de etapas anteriores del desarrollo capitalista mundial. ${ }^{10}$

En un plano ya más serio, el propio Theotonio dos Santos entabló una polémica con Lenin, que resulta interesante reconstituir para ver hasta qué punto la teoría de la dependencia y el marxismo-leninismo se movían en órbitas aparentemente muy cercanas, pero en el fondo harto distintas. Nos referimos a aquel texto en que Dos Santos afirma que "la dependencia, conceptuándola y estudiando su mecanismo y su legalidad histórica, significa no sólo ampliar la teoría del imperialismo sino también contribuir a su reformulación". ${ }^{11}$

¿De qué reformulación se trata exactamente? Según Theotonio dos Santos, de

[... algunos equívocos en que incurrió Lenin, al interpretar en forma superficial ciertas tendencias de su época. Lenin esperaba que la evolución de las relaciones imperialistas conducirían a un para-

\footnotetext{
10 André Gunder Frank, Lumpenburguesía: lumpendesarrollo, Santiago, Prensa Latinoamericana S.A., 1970, p. 37.

11 Theotonio dos Santos, Dependencia y cambio social, op. cit., pp. 41-42.
} 
sitismo en las economías centrales y su consecuente estancamiento y, por otro lado, creía que los capitales invertidos en el exterior por los centros imperialistas llevarían al crecimiento económico de los países atrasados.

$\mathrm{Al}$ respecto, Lenin dice textualmente lo siguiente:

La exportación del capital influye sobre el desarrollo del capitalismo en los países en que aquél es invertido, acelerándolo extraordinariamente. Si, por este motivo, dicha exportación puede, hasta cierto punto, ocasionar un cierto estancamiento del desarrollo en los países exportadores, esto se puede producir únicamente a costa de la extensión y del ahondamiento del capitalismo en todo el mundo. ${ }^{12}$

Afirmación errónea, a juicio de Dos Santos, porque:

En primer lugar, Lenin no estudió los efectos de la exportación de capital sobre las economías de los países atrasados. Si se hubiera ocupado del tema, hubiera visto que este capital se invertía en la modernización de la vieja estructura colonial exportadora y, por tanto, se aliaba a los factores que mantenían el atraso de estos países. Es decir, no se trataba de la inversión imperialista en general, sino de la inversión imperialista en un país dependiente. Este capital venía a reforzar los intereses de la oligarquía comercial exportadora, a pesar de que abría realmente una nueva etapa de la dependencia de dichos países.

Sí, pero no nos parece nada seguro que, de haberse Lenin ocupado del tema, hubiera modificado lo substancial de su afirmación, al menos en lo que a los países atrasados concierne, entre otras razones, porque Lenin no dice lo que Theotonio dos Santos le atribuye. En el resumen que éste hace de la tesis de aquél

12 Vladimir I. Lenin, El imperialismo, fase superior del capitalismo, Pekín, Ediciones en Lenguas Extranjeras, 1972, p. 80. 
hay una diferencia terminológica que, en el fondo, remite a una diferencia de conceptos y universos teóricos que es el origen de todo el malentendido: Lenin no afirma, en ningún momento, que las exportaciones de capital "llevarán al crecimiento económico de los países más atrasados", sino que dichas inversiones producirán en estos países un acelerado desarrollo del capitalismo que significará, a la postre, una extensión y ahondamiento de dicho modo de producción en escala mundial. Ahora bien, decir que desde 1916, fecha en que Lenin redactó dicho texto, hasta 1969 , en que Dos Santos escribe el suyo, no ha habido una extensión y un ahondamiento del capitalismo en América Latina, con desarrollo de las fuerzas productivas inclusive, es lisa y llanamente insostenible. ¿Qué ha ocurrido, si no, en nuestros países?

Que este desarrollo ha sido desigual y crítico en el sistema en su conjunto y en los países subdesarrollados en particular, así como la causa de la pauperización relativa y, a veces, absoluta de las masas trabajadoras, es un hecho que está fuera de duda; pero no debemos olvidar que, para Lenin, ello forma parte del concepto mismo de desarrollo del capitalismo, que, por lo tanto, no es equivalente a la expresión ideológica crecimiento económico. De no darse esas desigualdades y esa pauperización, anota Lenin en el mismo texto: "El capitalismo dejaría de ser capitalismo, pues el desarrollo desigual y el nivel de vida de las masas semihambrientas son las condiciones y las premisas básicas, inevitables, de este modo de producción". ${ }^{13}$

Lo que sucede es que Dos Santos se ubica en una perspectiva diferente, que involucra necesariamente la idea de que, a no ser por la dependencia, América Latina hubiera tenido un desarrollo mucho más acelerado y armonioso del que en realidad tuvo. Admite que hubo una "modernización", pero ella misma es reconceptualizada como elemento de perpetuación del atraso, en la medida en que éste no es definido en relación con una situación existente en el momento dado, sino en relación con una situación virtual: el desarrollo independiente del capitalismo en América Latina.

$13 \quad$ Ibid., p. 77. 
Y es que, de hecho, en los autores de la teoría de la dependencia existe, en mayor o menor grado, una suerte de nostalgia del desarrollo capitalista autónomo frustrado; esto es, justamente lo que confiere a su discurso un permanente hálito ideológico nacionalista y determina que la dependencia se erija en dimensión omnímoda cuando no única del análisis. Lo que no quiere decir - y esto hay que dejarlo bien sentado— que ellos hayan propugnado el desarrollo capitalista autónomo como panacea para nuestros males: mientras para el nacionalismo reformista este tipo de desarrollo seguía presentándose como el camino más expedito hacia la Tierra Prometida, para el nacionalismo revolucionario ya no era más que un paraíso irremisiblemente perdido:

Pero al aislar a su país, no de toda relación, sino de la dependencia extranjera [escribe Gunder Frank], los gobiernos del Doctor Francia y sus sucesores, los López, lograron un desarrollo nacional estilo bismarkiano o bonapartista como ningún otro país latinoamericano de la época. Construyeron un ferrocarril con capital propio; desarrollaron industrias nacionales y contrataron técnicos extranjeros - pero sin admitir inversiones - como lo harían los japoneses, décadas más tarde; establecieron la educación primaria fiscal y gratuita, casi eliminando — según testigos contemporáneos—el analfabetismo; y, es más, expropiaron a los grandes latifundistas y comerciantes, en beneficio del régimen más popular de América, con apoyo de los indígenas guaraníes. Cuando esta política "americana" — que, por cierto, también devino expansionista a mediados del siglo— tropezó con las ambiciones del "partido europeo" en Buenos Aires, Montevideo, Río de Janeiro y en la propia Europa, la Guerra de la Triple Alianza venció a la nación paraguaya y diezmó hasta 6/7 de su población masculina. Luego, el Paraguay también se abrió a la "civilización". ${ }^{14}$

Nostalgia del capitalismo nacional perdido que no deja de ser, por lo menos, paradójica si se piensa que este texto fue escrito

14 André Gunder Frank, Lumpenburguesía: lumpendesarrollo, op. cit., pp. 72-73. 
en el momento en que el futuro socialista estaba ya instalado en América, con la Revolución Cubana como bandera.

La presencia de este trasfondo desarrollista o nacionalista no anula, por supuesto, la validez de muchos análisis concretos, ni resta mérito a investigaciones como la del propio Theotonio dos Santos en El nuevo carácter de la dependencia, hito notable en el desarrollo de nuestra sociología, que sólo citamos a título de ejemplo, ya que no es nuestra intención repartir premios y castigos ni hacer historia, sino solamente señalar, con la mayor franqueza y precisión, algunos puntos de discrepancia con respecto a la corriente sociológica más vigorosa y difundida en la última década.

Entre los problemas que esta corriente presenta está, naturalmente, el derivado del uso totalitario de los conceptos dependencia y dependiente, cuyos límites de pertinencia teórica jamás han logrado ser definidos y cuya insuficiencia teórica es notoria, sobre todo cuando se trata de elaborar vastos esquemas de interpretación del desarrollo histórico de América Latina.

Que este desarrollo, en el siglo XIX, por ejemplo, resulta absolutamente inexplicable si no se toma en cuenta la articulación de nuestras sociedades a la economía mundial, es algo que está fuera de toda duda, como lo está también la enorme contribución que para el conocimiento de este problema han realizado los estudios sobre dependencia. Admitido lo cual, uno no puede dejar de constatar, sin embargo, las claras insuficiencias explicativas del concepto dependencia, sobre todo cuando se dejan de lado conceptos básicos como: fuerzas productivas, relaciones sociales deproducción, clases y lucha de clases; o bien, se los reemplaza por categorías tan ambiguas como: expansión hacia fuera, colonias de explotación o de población, grupos tradicionales y modernos, integración social, etcétera.

Tenemos naturalmente en mientes el libro Desarrollo y dependencia en América Latina, de Cardoso y Faletto, cuyas tesis generales se vuelven incluso difíciles, si es que no imposibles de organizar y discutir, en la medida en que todo el discurso teórico de los autores parece remitir constantemente a un doble código 
y ser susceptible por lo tanto de dos lecturas: una marxista y otra desarrollista, según que uno acentúe tal o cual afirmación, ponga de relieve uno u otro concepto, o, simplemente, atribuya diferente significado a los términos tantas veces entrecomillados.

Pero si no nos fijamos ya en los ambiguos enunciados teóricos, sino que reflexionamos sobre los análisis históricos concretos, descubrimos de inmediato las lagunas dejadas por la no aplicación de conceptos fundamentales como los arriba señalados. Es lo que ocurre por ejemplo en el capítulo III del libro mencionado, intitulado "Las situaciones fundamentales en el período de reexpansión hacia fuera", donde parecen escaparse muchos elementos sin los cuales se torna incomprensible la historia - incluso meramente económica- de los países latinoamericanos en ese período y aun más allá de él. Tales elementos son, entre otros, los siguientes:

Primero, el carácter básicamente precapitalista de América Latina al iniciarse ese período, lo que implica ya cierto grado de desarrollo de las fuerzas productivas y ciertas relaciones sociales de producción; es decir, una articulación concreta de modos de producción y, por lo tanto, de clase, que de alguna manera determinará la forma de articulación de nuestros países al capitalismo mundial, en un movimiento desde luego dialéctico.

Segundo, el proceso de acumulación originaria que en esas condiciones tenía que darse y se dio; no porque América Latina no hubiera contribuido desde antaño a la acumulación originaria en Europa, sino justamente por esto: porque su situación colonial le impidió realizar internamente dicho proceso.

Tercero, y lo que es más importante, toda la lucha de clases que ello implicó, aunque sólo fuese por hechos como el despojo bárbaro a los campesinos desde México hasta Chile, la confiscación de los bienes eclesiásticos y las revoluciones liberales en sí mismas, que no necesariamente fueron un juego de niños.

De estos hechos se hace caso omiso en el libro en cuestión, pese a que sin ellos resulta imposible entender la Revolución Mexicana, por ejemplo, sin la cual es incomprensible, a su vez, el ulterior desarrollo del capitalismo en México. De la misma ma- 
nera que, sin hablar de los desembarcos y ocupaciones militares del Caribe y Centroamérica por las fuerzas imperialistas, cosa igualmente omitida en Desarrollo y dependencia, es absolutamente imposible explicarse el desarrollo de esta área, incluyendo la Revolución Cubana. Tales actos, no lo olvidemos, crearon situaciones verdaderamente coloniales (Puerto Rico) o semicoloniales (Cuba, Santo Domingo, Haití, Nicaragua, etc.), que el ambiguo término de "enclave" estálejos de describir y, menos aún, de captar en su significación histórica.

No se trata, pues, de reclamar el análisis de los modos de producción y de las clases sociales por razones morales o de principios, sino por ser categorías teóricas fundamentales, sin las cuales ni siquiera se puede rendir cuenta del desarrollo puramente económico de la sociedad. Los propios autores de Desarrollo y dependencia parecen admitirlo implícitamente cuando escriben: “¿Hasta qué punto el hecho mismo de la Revolución Mexicana, que rompió el equilibrio de las fuerzas sociales, no habrá sido el factor fundamental del desarrollo logrado posteriormente?"; 15 pero son, justamente, la lógica y riqueza de procesos como éste las que dejan escapar al adoptar un modelo teórico que parte del supuesto de que "es el tipo de integración de las clases, y no su lucha, uno de los 'condicionantes' principales del proceso de desarrollo". ${ }^{16}$

En general, es el análisis de las clases y su lucha lo que constituye el talón de Aquiles de la teoría de la dependencia. Para empezar, los grandes y casi únicos protagonistas de la historia que esa teoría presenta son las oligarquías y burguesías, o, en el mejor de los casos, las capas medias; cuando los sectores populares aparecen, es siempre como una masa amorfa y manipulada por algún caudillo o movimiento populista; de suerte que uno se pregunta por qué en Brasil, por ejemplo, se estableció un régimen claramente anticomunista (y no antipopulista), o cómo fue posible que

\footnotetext{
15 Fernando Henrique Cardoso y Enzo Faletto, Desarrollo y dependencia en América Latina, México, Siglo XXI, 1970, 2ª ed., pp. 8-9.

16 Ibid., p. 17.
} 
en Chile se constituyera "de repente" un gobierno como el de la Unidad Popular. Además, no deja de ser sintomático el hecho de que, en la década pasada, no se haya producido un solo libro sobre las clases subordinadas a partir de aquella teoría. ${ }^{17}$

En fin, el propio estudio de la burguesía y sus fracciones parece haberse visto interferido por un inadecuado manejo del marxismo. Tal es el caso de los análisis sobre la burguesía nacional (media y pequeña), a la que comienza por pedírsele virtudes revolucionarias que jamás poseyó, para luego negar pura y llanamente su existencia en América Latina. Con el loable propósito de evitar las posiciones reformistas, en este como en otros aspectos, se cae en el otro extremo, la ultraizquierdización del análisis, al borrar de una plumada todas las contradicciones secundarias de la sociedad y la posibilidad de actuar sobre ellas.

Algo semejante ocurre con los estudios sobre la llamada "oligarquía", a la que se le atribuye, de derecho, una contradicción antagónica con la burguesía industrial; para pasar a señalar, de inmediato, que la originalidad del capitalismo "dependiente" frente al capitalismo "clásico" determina la abolición de aquella contradicción. Razonamiento que uno tiene dificultad en seguir, aunque sólo fuese por la ambigüedad inherente al término "oligarquía". En todo caso, si se trata de la aristocracia feudal o esclavista, ella ha sido eliminada de la escena social latinoamericana hace ya bastante tiempo; o convertida, hasta en sus últimos reductos en Ecuador o Bolivia, en fracción terrateniente semicapitalista; así que por ese lado, no se ve mayor diferencia de fondo entre el desarrollo "clásico" y el nuestro. Y si por "oligarquía" se entiende simplemente el sector agrario de la burguesía, no se ve en virtud de qué habría que esperar su total eliminación. El desarrollo del capitalismo, clásico o no, convierte a esta fracción de clase en sector no hegemónico, como está ocurriendo por doquier en América Latina, mas esto es ya otro asunto.

17 Existe, por supuesto, el libro ya mencionado de Rodolfo Stavenhagen, pero cuyo marco teórico poco tiene que ver con la teoría de la dependencia. 
Observación que nos coloca, además, frente a otro problema presente en la mayoría de los estudios sobre dependencia; problema que consiste en el manejo teóricamente arbitrario de dos modelos: el de un capitalismo "clásico" y un capitalismo "dependiente", que, a la postre, no son otra cosa que dos tipos ideales, en el sentido weberiano del término.

Meditemos, por ejemplo, en toda la ambigüedad de este pasaje extraído de Desarrollo y dependencia en América Latina:

Metodológicamente no es lícito suponer — dicho sea con mayor rigor-que en los países "en desarrollo" se esté repitiendo la historia de los países desarrollados. En efecto, las condiciones históricas son diferentes: en un caso se estaba creando el mercado mundial paralelamente al desarrollo, gracias a la acción de la denominada bourgeoisie conquerante; y en el otro se intenta el desarrollo cuando ya existen relaciones de mercado, de índole capitalista, entre ambos grupos de países, y cuando el mercado mundial se presenta dividido entre el mundo capitalista y el socialista. Tampoco basta considerar las diferencias como desviaciones respecto de un patrón general de desarrollo, pues los factores, las formas de conducta y los procesos sociales y económicos, que a primera vista constituyen formas desviadas o imperfectas de realización del patrón clásico de desarrollo, deben considerarse, más bien, como núcleos de análisis destinados a hacer inteligible el sistema económico social. ${ }^{18}$

"La historia no se repite": he ahí una fórmula de perfiles peligrosos, puesto que puede conducir directamente al empirismo, si es que no se precisa su alcance y su contenido. Entendida en el sentido de una originalidad absoluta de nuestro proceso histórico, esa fórmula ha sembrado, de hecho, una enorme confusión en las ciencias sociales latinoamericanas, como es fácil comprobar con sólo seguir la discusión sobre los modos coloniales de producción, supuestamente irreductibles a cualquier categoría antes conocida.

18 Fernando Henrique Cardoso y Enzo Faletto, Desarrollo y dependencia en América Latina, op. cit., p. 33. 
Que la historia de América Latina no es una forma "desviada o imperfecta de realización del patrón clásico de desarrollo", en eso estamos de acuerdo con Cardoso y Faletto; mas no por las razones que ellos aducen, sino porque plantear el problema en términos de "patrones" o "modelos" nos parece sustancialmente incorrecto. Lo que existe, al menos desde un punto de vista marxista, no son "patrones" sino leyes, como las del desarrollo del capitalismo, por ejemplo, que se cumplen en América Latina como por doquier, dentro de condiciones históricas determinadas, claro está, pero cuyo estatuto tiene que ser definido con precisión si no se quiere caer en una teoría de la irreductible singularidad. Son esas "condiciones" (sobredeterminaciones) las que aceleran, por ejemplo, el paso de la fase competitiva a la fase monopólica; o las que ahorran al capitalismo periférico la necesidad de una revolución industrial, al mismo tiempo que entregan a sus masas trabajadoras a una doble explotación: la de la burguesía local, más la de la burguesía imperial, o inversamente, si se quiere. Y es en esto, así como en la articulación específica de varios modos de producción, y de varias fases de un mismo modo, donde reside la particularidad del desarrollo histórico latinoamericano, en el que no cabe buscar entonces una excesiva "originalidad". La historia no se repite al pie de la letra, es cierto, pero "milagros" como el brasileño o como el del propio Pinochet tampoco son del todo inéditos. Antes que "milagros" de la dependencia son milagros del capitalismo tout court.

Por eso conviene recordar, metodológicamente, que en la fórmula "capitalismo dependiente" hay algo que es un sustantivo (capitalismo) y algo que es un adjetivo (dependiente) y que, por lo tanto, la esencia de nuestra problemática no puede descubrirse haciendo de la oposición capitalismo clásico / capitalismo dependiente, el rasgo de mayor pertinencia, sino a partir de las leyes que rigen el funcionamiento de todo capitalismo. El mantenimiento de aquella oposición como eje central del análisis no es, por lo demás, otra cosa que el testimonio fehaciente de cierta "continuidad en el cambio", toda vez que representa la traducción a términos aparentemente marxistas del clásico binomio cepalino 
"centro/periferia", que Frank, a su turno, retomó con el nombre de "metrópoli/satélite".

En su afán de mantenerse fiel a la teoría de la dependencia, incluso un autor tan riguroso y ceñido al marxismo como Ruy Mauro Marini se ve obligado a estilizar tanto las situaciones, que a la postre termina trabajando con modelos antes que con leyes. En los capítulos 5 y 6 de su libro Dialéctica de la dependencia, por ejemplo, nos describe una situación específica del capitalismo latinoamericano que consistiría en la existencia de una estructura productiva basada en la sobreexplotación del obrero; la que, a su vez, determinaría una estructura de la circulación escindida: por un lado, una esfera orientada hacia el consumo suntuario, que sería la verdaderamente dinámica; y, por otro, la del consumo obrero, deprimida y en constante estancamiento. De suerte que, mientras en la "economía clásica" es y habría sido el consumo de las masas el motor principal de la industrialización, en la "economía dependiente" no ocurriría nada parecido, creándose así un problema de realización que originaría una tendencia de expansión hacia el exterior, y que sería la causa fundamental del subimperialismo.

Muchos de los problemas planteados por Marini son desde luego ciertos; queda, sin embargo, la inquietud de saber si entre el capitalismo llamado clásico y el dependiente existe realmente una diferencia cualitativa que autorice a formular leyes específicas para uno y otro; ${ }^{19}$ o si Marini no está simplemente cargando las tintas a fin de volver operables los modelos. Se puede poner en duda, por ejemplo, que a la Francia de 1930 o 1940 se le hubiera podido aplicar esta afirmación con la que el autor cree describir una especificidad del capitalismo dependiente:

19 Punto sobre el cual las formulaciones teóricas de Marini se vuelven, por lo demás, equívocas. En la p. 81 de su Dialéctica de la dependencia (México, Era, 1973), habla de "las leyes de desarrollo del capitalismo dependiente"; en la 83, se refiere, en cambio a "la manera como se manifiestan en esos países [los de América Latina] las leyes de desarrollo del capitalismo dependiente"; mientras en otros pasajes habla de "los grados intermedios mediante los cuales esas leyes [las leyes generales del capitalismo] se van especificando" (p. 99); afirmaciones que no son exactamente equivalentes. 
El abismo existente allí, entre el nivel de vida de los trabajadores y el de los sectores que alimentan a la esfera alta de la circulación, hace inevitable que productos como automóviles, aparatos eléctricos, etc., se destinen necesariamente a esta última. ${ }^{20}$

Como se puede dudar también de que ramas industriales como la electromecánica (televisores, radiorreceptores, etc.), la de productos metálicos (muebles, por ejemplo) o petroquímicos (utensilios de material plástico), no estén dinamizadas en gran parte de los países latinoamericanos gracias a cierto consumo popular. Después de todo, la imagen de las masas semihambrientas pero provistas de transistores, parece ser más bien "típica" de las situaciones de subdesarrollo. ${ }^{21}$

Éstas son observaciones con las cuales no queremos decir — repitámoslo una vez más - que el desarrollo de los países dependientes ocurra en la misma forma que el de los países capitalistas hoy "avanzados"; ni que la situación de las masas sea idéntica en ambos casos. Tanto la dominación y explotación imperialista, como la articulación particular de modos de producción que se da en cada una de nuestras formaciones sociales, determinan que incluso las leyes propias del capitalismo se manifiesten en ellas de manera más o menos acentuada o cubiertas de "impurezas" (como en toda formación social, por lo demás); pero sin que ello implique diferencias cualitativas capaces de constituir un nuevo objeto teórico, regido por leyes propias, ya que la dependencia no constituye un modo de producción sui generis (no existe ningún

20 Ruy Mauro Marini, Dialéctica de la dependencia, op. cit., p. 72.

21 Incluso decir, como lo hace Marini, que el proceso de industrialización en América Latina se frenó por "la comprensión permanente que ejercía la economía exportadora sobre el consumo individual del obrero" (ibid., p. 61) es sólo parcialmente cierto. La situación que describe Peter Klaren, por ejemplo, en su libro La formación de las haciendas azucareras y los orígenes del Apra (Lima, Moncloa, 1970), no es una situación en la cual los obreros de la plantación no tienen acceso a bienes industriales; la tienen, y justamente por eso la compañía redobla su negocio instalando grandes tiendas donde se venden artículos... importados, cosa que está lejos de contribuir al desarrollo industrial del Perú por razones obvias, pero que no corresponden al mecanismo descrito por Marini. 
"modo de producción capitalista dependiente", como en cierto momento llegó a decirse), ni tampoco una fase específica de modo de producción alguno (comparable a la fase imperialista del modo de producción capitalista, por ejemplo), sino que es la forma de existencia concreta de ciertas sociedades ${ }^{22}$ cuya particularidad tiene que ser desde luego estudiada.

Nuestra tesis es, por lo tanto, la de que no hay ningún espacio teórico en el que pueda asentarse una teoría de la dependencia, marxista o no, por la misma razón que no la hubo ni en la Rusia de Lenin, ni en la China de Mao; aunque en todos estos casos haya, naturalmente, complejos objetos históricos concretos cuyo conocimiento es necesario producir a la luz de la teoría marxista.

Además de los problemas ya mencionados, la teoría de la dependencia presenta otro, que consiste en el tratamiento no dialéctico de las relaciones entre lo externo y lo interno; lo que lleva, en muchos casos, a la postulación de esquemas mecánicos en los que no queda otro motor de la historia que la determinación externa. Aquí, como en puntos anteriores, conviene partir de las tesis de Frank, que son las más elocuentes al respecto.

En el "Mea culpa", publicado como introducción a Lumpenburguesía: lumpendesarrollo, el autor no deja de expresar su asombro por el hecho de que Ernst Halperin haya interpretado su libro Capitalismo y subdesarrollo en América Latina como "una presentación impresionante y convincente de la manera en que, a partir de la Conquista, el destino de los latinoamericanos siempre ha sido afectado por acontecimientos fuera de su continente y fuera de su control". ${ }^{23}$

22 Por eso, aun aquel rasgo que Marini señala como más típico de éstas, es decir, la sobreexplotación, que se traduce por la comprensión del consumo individual del obrero, bien podría enunciarse con un nombre bastante clásico: proceso de pauperización, que en coyunturas a veces prolongadas se realiza, incluso, en términos absolutos. Y en cuanto al problema de la realización de la plusvalía, que el mismo autor plantea, tampoco es del todo inédito, basta recordar la polémica que al respecto mantuvo Lenin con los populistas rusos.

23 André Gunder Frank, Lumpenburguesía: lumpendesarrollo, op. cit., p. 14. 
Frank arguye entonces que ése no es su punto de vista, y para comprobarlo, cita este pasaje del libro comentado por Halperin:

Para la generación del subdesarrollo estructural, más importante aún que la succión de su excedente económico [...] es la impregnación de la economía nacional del satélite con la misma estructura capitalista y sus contradicciones fundamentales $[. .$.$] que organiza$ y domina la vida nacional de los pueblos en lo económico, político y social. ${ }^{24}$

Luego añade que,

al contrario de aquella "impresión" [la de Halperin], la dependencia no debe ni puede considerarse como una relación meramente "externa" impuesta a todos los latinoamericanos desde afuera y contra su voluntad; sino que es igualmente una condición "interna" e integral de la sociedad latinoamericana, que determina a la burguesía dominante en Latinoamérica; $y$, a la vez, es consciente y gustosamente aceptada por ella. ${ }^{25}$

Frank se defiende pues, aquí como en otros ensayos ${ }^{26}$ de haber realizado y difundido un tipo de análisis en el cual las determinaciones externas sustituyen y anulan a las determinaciones o contradicciones internas, como núcleo explicativo del desarrollo de América Latina.

Ahora bien, el comentario de Halperin es, en realidad, una caricatura de las tesis de Frank; pero como toda caricatura, no hace más que acentuar algunos rasgos del original. Por eso, lo que a la postre resulta asombroso no es tanto que Halperin y otros hayan leído sin la debida atención a Frank, sino que Frank

$24 \quad$ Ibid., p. 15.

25 Ibid.

26 André Gunder Frank, "La dependencia ha muerto, viva la dependencia y la lucha de clases", en Sociedad y desarrollo, No. 3, Santiago de Chile, CESO-PLA, julio-septiembre de 1972, p. 228. 
se haya leído mal a sí mismo o no haya tomado conciencia de las implicaciones teóricas de lo que escribía. Suyas son, después de todo, las siguientes afirmaciones:

Si es el status de satélite el que genera el subdesarrollo, una relación más débil o menos estrecha entre metrópoli y satélite puede producir un subdesarrollo estructural menos profundo y/o permitir mayores posibilidades de desarrollo local. ${ }^{27}$

Y:

Es importante también para confirmar nuestra tesis, el hecho característico de que ciertos satélites lograron avances temporarios, en el sentido del desarrollo durante guerras o depresiones ocurridas en la metrópoli, las cuales debilitaron o redujeron momentáneamente la dominación de ésta sobre la vida de los satélites. ${ }^{28}$

¿Piensa realmente Frank que esos avances se debieron a que los satélites se "desimpregnaron" en ese momento de su estructura capitalista, o más bien realiza un cuasi experimento destinado a mostrar cómo un elemento exterior (crisis o depresión en la metrópoli) determina, en este caso favorablemente, el desarrollo del satélite? Sus análisis concretos sobre Chile no dejan lugar a dudas:

Estimulada por la depresión y por la caída de las importaciones industriales provocadas por la guerra, la producción de la manufactura chilena aumentó en un 80\% entre 1940 y 1948; pero sólo un 50\% entre 1948 y 1960 . En otras palabras, durante el primer lapso de ocho años la tasa no acumulativa anual de la producción industrial fue del $10 \%$; y en los doce años que siguieron a la recu-

\footnotetext{
27 André Gunder Frank, "Chile: el desarrollo del subdesarrollo", en Montbly Review. Selecciones en castellano, $2^{a}$ ed., s.f., p. 20.

28 Ibid., p. 21.
} 
peración metropolitana, la tasa de crecimiento de la manufactura bajó al 4\%. Desde entonces el promedio siguió descendiendo hasta tocar el cero; y, a veces, más abajo. ${ }^{29}$

Que los autores cepalinos vean el desarrollo industrial de Chile, a principios de los años cuarenta, como un desarrollo "inducido" por una crisis en las "economías centrales", que obligó a realizar una "sustitución de importaciones" en los países "periféricos”, parece lo más normal del mundo: se trata de una interpretación prudente y oficial. Pero que un autor como Frank ignore la existencia de ciertas luchas sociales en Chile, el triunfo del Frente Popular de Aguirre Cerda en el año 38, y la consiguiente implantación de una política planificada que "algo" tuvo que ver con la industrialización del país (en condiciones nacionales e internacionales determinadas, claro está), es un hecho ya más grave. Demuestra los límites a los que puede llegar una "revolución" teórica que, para superar al marxismo "tradicional”, no vacila en reemplazar la lucha de clases por la sustitución de importaciones como motor de la historia.

Ninguno de los teorizantes de la dependencia ha llegado, desde luego, a manejar un esquema tan simplista como el de Frank. Sin embargo, ideas como la de que la industrialización de América Latina es explicable por las sucesivas crisis en el "centro" parecen ser harto difundidas, pese a que basta con revisar las tasas de crecimiento de la industrial fabril, en cualquier país latinoamericano entre 1929 y 1935 , por ejemplo, para darse cuenta de que se trata de un simple mito. Mas el hecho mismo de que el mito haya podido prender, demuestra hasta qué punto llegó a arraigar en nuestra sociología el esquema determinista mecánico difundido por Frank y los autores cepalinos. ${ }^{30}$

29 André Gunder Frank, Lumpenburguesía: lumpendesarrollo, op. cit., p. 142.

30 Quiero hacer notar que todos los autores dependentistas, sin excepción, aceptaron la tesis de la industrialización "por substitución de importaciones", al menos hasta el momento en que este trabajo fue redactado (nota de 1979). 
Es cierto que en autores como Cardoso y Faletto hay un importante esfuerzo por superar dicho esquema a través de planteamientos como el siguiente:

Se hace necesario, por lo tanto, definir una perspectiva de interpretación que destaque los vínculos estructurales entre la situación de subdesarrollo y los centros hegemónicos de las economías centrales, pero que no atribuya a estos últimos la determinación plena de la dinámica del desarrollo. En efecto, si en las situaciones de dependencia colonial es posible afirmar con propiedad que la historia y - por ende el cambio_ - aparece como reflejo de lo que pasa en la metrópoli, en las situaciones de dependencia de las "naciones subdesarrolladas” la dinámica social es más compleja. En ese último caso hay, desde el comienzo, una doble vinculación del proceso histórico que crea una "situación de ambigüedad", o sea, una contradicción nueva. Desde el momento en que se plantea como objetivo instaurar una nación — como en el caso de las luchas anticolonialistas-, el centro político de la acción de las fuerzas sociales intenta ganar cierta autonomía al sobreponerse a la situación de mercado; las vinculaciones económicas, sin embargo, continúan siendo definidas objetivamente en función del mercado externo y limitan las posibilidades de decisión y acción autónomas. En eso radica, quizá, el núcleo de la problemática sociológica del proceso nacional de desarrollo en América Latina. ${ }^{31}$

Pero aun aquí las limitaciones son evidentes. En primer lugar, y como lo señaló oportunamente Weffort, ${ }^{32}$ la contradicción entre un Estado nacional políticamente independiente y una economía nacional dependiente (del mercado mundial) resulta abstracta, por decir lo menos, si es que no se liga a un riguroso análisis de

31 Fernando Henrique Cardoso y Enzo Faletto, Desarrollo y dependencia en América Latina, op. cit., pp. 28-29.

32 Francisco C. Weffort, Notas sobre la "teoría de la dependencia": ¿teoría de clases o ideología nacional?, México, ABIIS-UNAM, s.f. 
clase. En el caso ecuatoriano, por ejemplo, ¿qué contradicción podía haber entre el Estado nacional de la incipiente burguesía agromercantil y la economía mundial de mercado, siendo que esa burguesía se había sumado a la lucha independentista justamente para conseguir la abolición de las trabas comerciales impuestas por España, que le impedían desarrollarse como clase? Si contradicción hubo entre Estado independiente e incorporación al mercado mundial en el caso mencionado, no fue otra que la que se estableció entre esa burguesía y los terratenientes feudales, cuyos rudimentarios "obrajes" no tardaron en desaparecer ante la competencia de los géneros importados. Es decir, una contradicción de clase que aquí remitía, incluso, a una contradicción entre modos de producción; que naturalmente, no dejó de reflejarse a nivel del Estado nacional, y en las relaciones de éste con los centros metropolitanos. Es por lo tanto esa contradicción interna - a cuyo desarrollo desde luego no es ajeno el de la economía capitalista mundial— la que permitirá comprender los aspectos contradictorios y no contradictorios de la relación entre el Estado ecuatoriano y el mercado externo.

En segundo lugar, la aseveración de que "en las situaciones de dependencia colonial es posible afirmar con propiedad que la historia —y por ende, el cambio— aparece como reflejo de lo que pasa en la metrópoli”, es profundamente reveladora de cómo el esquema frankiano no está totalmente superado por Cardoso y Faletto; sino sólo relegado a la etapa en que no existía aún el Estado nacional, único elemento capaz de introducir cierto nivel de contradicción. Pero ¿cómo explicar, a partir de esta visión nacionalista de la historia, los levantamientos de los encomenderos a mediados del siglo XVI; la secular lucha de los araucanos; las continuas rebeliones populares y, finalmente, la Independencia? ¿Fue esta última, por ejemplo, un simple "reflejo" de la crisis por la que en ese momento atravesaba la Metrópoli?

Dicha crisis fue sin duda uno de los elementos que configuraron la compleja situación en que pudo triunfar el movimiento independentista latinoamericano; mas ello no autoriza a establecer un determinismo tan mecánico, que bien podría llevarnos con 
igual legitimidad a afirmar que los tiempos han cambiado tanto que ahora la situación de las metrópolis es un "reflejo" de lo que sucede en las colonias, como los recientes acontecimientos de Portugal lo estarían demostrando.

Hay, pues, un problema en el tratamiento de la relación externo-interno, que, a nuestro juicio, no ha sido adecuadamente resuelto por la teoría de la dependencia. De hecho, ésta parece oscilar entre una práctica en la que la determinación ocurre siempre en sentido único (lo que sucede en el país dependiente es resultado mecánico de lo que ocurre en la metrópoli), y una "solución" teórica que es estrictamente sofística y no dialéctica: no hay, se dice, diferencia alguna entre lo externo y lo interno, puesto que el colonialismo o el imperialismo actúan dentro del país colonizado o dependiente. Esto último es cierto, ya que de otro modo se trataría de elementos no pertinentes, ajenos simplemente al objeto de estudio; pero hay un sofisma en la medida en que de esa premisa verdadera se derive una conclusión que ya no lo es: ese "estar adentro" no anula la dimensión externa del colonialismo o el imperialismo, sino que más bien la plantea en toda su tirantez.

El capital imperialista invertido en la explotación del petróleo ecuatoriano, por ejemplo, está en el interior del país, forma parte de la estructura interna del Ecuador y hasta constituye, en el momento actual, el polo hegemónico de su economía. Sólo que, si por arte de magia suprimimos la dimensión externa del problema (externa a la formación social ecuatoriana), tendríamos que concluir, lisa y llanamente, que el Ecuador es un país imperialista puesto que el capital monopólico constituye el polo dominante de su economía. Desgraciadamente, lo que penetra en cada nación "dependiente" no es el concepto de imperialismo, sino el imperialismo "de carne y hueso", con todas las relaciones internacionales que ello implica (relaciones que, por supuesto, no pueden entenderse sin aquel concepto).

Weffort tenía razón de hacer notar que "la incorporación de la dimensión eterna es obligatoria, pues de otro modo no tendría sentido hablar de las relaciones internas como relaciones de 
dependencia", 33 pero su error consistió en creer que el problema podía resolverse mediante la simple supresión de las premisas nacionales de que había partido la teoría de la dependencia, cuando, en realidad, era menester buscar el fundamento de la clase de la relación entre naciones y tratar, de manera dialéctica, la dimensión externa que ello implica necesariamente.

"En oposición a la concepción metafísica del mundo, la concepción dialéctica materialista del mundo sostiene que, a fin de comprender el desarrollo de una cosa, debemos estudiarla por dentro y en sus relaciones con otras cosas; dicho de otro modo, debemos considerar que el desarrollo de las cosas es un automovimiento, interno y necesario, y que, en su movimiento, cada cosa se encuentra en interconexión e interacción con las cosas que lo rodean", escribe Mao en su conocido texto "Sobre la contradicción". ${ }^{44}$ Gunder Frank arguye que, sin embargo, nadie ha logrado todavía "clarificarla suficientemente [...] cómo debe distinguirse exactamente entre las contradicciones 'externas' y las 'internas' en el proceso, tal como éste se desenvuelve en una parte determinada del sistema imperialista". ${ }^{35} \mathrm{Y}$ es comprensible que esto le ocurra. Para Mao, ese misterioso "interno" está constituido por una articulación específica de contradicciones "entre las clases productivas y las relaciones de producción, entre las clases y entre lo viejo y lo nuevo" ${ }^{36}$ en cada formación social concreta, llámese ésta China, Colombia o Argentina; articulación interna que resulta imposible imaginar siquiera en un esquema como el de Frank, en donde los conceptos de fuerzas productivas, relaciones de producción, estructura y lucha de clases están simplemente ausentes.

Este error de la teoría de la dependencia, que consiste en tratar de explicar siempre el desarrollo de una formación social a par-

\section{Ibid.}

34 Mao Tse-tung, Cinco tesis filosóficas, Pekín, Ediciones en Lenguas Extranjeras, 1971, p. 49.

35 André Gunder Frank, Lumpenburguesía: lumpendesarrollo, op. cit., p. 51.

36 André Gunder Frank, "La dependencia ha muerto, viva la dependencia y la lucha de clases”, op. cit., p. 228. 
tir de su articulación con otras formaciones, determina que aun trabajos tan sólidos como Dialéctica de la dependencia desemboquen en un verdadero callejón sin salida. Como se sabe, Marini sostiene en este libro que en la relación entre países industrializados y países dependientes, en la segunda mitad del siglo XIX - primera fase de nuestra dependencia-, se encuentra ya la clave para entender las diferencias del desarrollo de estas dos áreas. $\mathrm{Y}$ aduce para ello buenas razones.

En primer lugar:

El fuerte incremento de la clase obrera industrial y, en general, de la población urbana ocupada en la industria y en los servicios, que se verifica en los países industriales, en el siglo pasado, no hubiera podido tener lugar si éstos no hubieran contado con los medios de subsistencia de origen agropecuario. Esto fue lo que permitió profundizar la división del trabajo y especializar a los países industriales como productores mundiales de manufacturas. ${ }^{37}$

En segundo lugar, la propia implantación del modo de producción específicamente capitalista en Europa, basado en la plusvalía relativa en lugar de la absoluta, no puede explicarse sin considerar la afluencia de productos agropecuarios provenientes de los países dependientes; productos que, obtenidos a precios cada vez más deteriorados, abarataban en el Viejo Continente el valor real de la fuerza de trabajo.

En fin, y coadyuvando en el mismo sentido, tendríamos el flujo de materias primas desde la periferia hacia el centro del sistema.

He ahí, según Marini, el anverso de esta medalla llamada dependencia. Su reverso, que es el que más nos interesa, estaría, a su turno, constituido por un contrario dialéctico. Esa misma producción exportable, que hace posible la implantación de un modo de producción específicamente capitalista en los países industrializados, tiene como contrapartida, en los países depen-

37 Ruy Mauro Marini, Dialéctica de la dependencia, op. cit., p. 21. 
dientes, el establecimiento de un modo de producción basado en la sobreexplotación; es decir, en la remuneración permanente del trabajo por debajo de su valor; sobreexplotación que, a su vez, se convierte en un freno para el desarrollo de nuestros países, tal como se vio en páginas anteriores.

Ahora bien, la novedad del esquema de Marini no está en señalar la existencia de un intercambio desigual entre naciones, con la consiguiente transferencia de valores y, en última instancia, de plusvalía; ni en anotar que la baja remuneración de los trabajadores constituye un escollo para la creación de un amplio mercado interno en América Latina. Tampoco en recordar todas las tropelías y exacciones que el imperialismo ha realizado, y realiza, en nuestros países, cosa que Marini da por sabida. Lo nuevo está en establecer una relación directa entre la articulación países industrializados-países dependientes (causa) y el desarrollo interno de cada una de esas economías que de ahí se derivaría (efecto). Y es en este punto, precisamente, donde el esquema de Marini se torna cuestionable, no por falta de coherencia lógica ni de fuerza ideológica, sino porque la realidad histórica se resiste a encajar en él.

En efecto, basta pensar en dos casos concretos de la historia de América Latina - y no muy marginales que se diga — para que la relación causal establecida por Marini se rompa en uno u otro sentido. En el primer caso que tenemos en mientes, el de Brasil, uno puede admitir en rigor la tesis de la sobreexplotación a condición de no poner reparos teóricos a su concepto mismo (remuneración permanente de la fuerza de trabajo por debajo de su valor) y de entenderlo más bien a partir del "sentido común"; pero en cambio resulta imposible concebir siquiera cómo las exportaciones de café brasileño habrían podido abatir el valor real de la fuerza de trabajo en Europa, y contribuir con ello al proceso que Marini señala (paso de la plusvalía absoluta a la plusvalía relativa), ya que se trata de un producto netamente superfluo desde el punto de vista de la reproducción de la fuerza de trabajo y cuyo principal consumidor ni siquiera fue la clase obrera. 
En el otro caso significativo, el de la Argentina, uno puede aceptar la incidencia de la exportación de cereales y carnes en la disminución del valor real de la fuerza de trabajo en Inglaterra, por ejemplo, pero entones resulta harto difícil sostener que ello haya tenido como contrapartida la remuneración de la fuerza de trabajo argentina por debajo de su valor, ni impedido la creación de un mercado interno para la industria de este país. Las masas argentinas de ese período fueron de las pocas aceptablemente nutridas del mundo capitalista en general, y dicho país, el primero de América Latina en tener un mercado significativo para productos industriales.

Además, los mismos ejemplos del Brasil cafetalero y la Argentina cerealera y ganadera contradicen flagrantemente la afirmación de Marini en el sentido de que, sin la contribución de la economía agropecuaria latinoamericana, habría sido imposible liberar la mano de obra que Europa necesitaba para su desarrollo industrial. Las áreas abastecedoras de cereales y carne - que por lo demás no siempre coinciden con los países hoy subdesarrollados- y aun un área cafetalera como la del Brasil, se poblaron, en el período en cuestión, con inmigrantes extranjeros; esto es, con la población excedente de Europa.

$¿$ Quiere decir esto que las tesis de Marini no funcionan a nivel de formaciones sociales concretas o que, al menos, pierden pertinencia en algunas de ellas? ¿Deberían ubicarse entonces en un plano más general? Es posible que así sea, pero, en ese caso, ya no estamos ante un proceso de abstracción que lleve al descubrimiento de verdaderas leyes, sino ante generalizaciones cuyo estatuto teórico habría que precisar, definiendo, en primer término, los objetos mismos sobre los que recae la investigación, esto es, lo que Marini denomina respectivamente "economía clásica" y "economía dependiente".

Por su misma brillantez y rigor, el ensayo de Marini pone de relieve las fronteras insuperables dentro de las cuales se mueve toda la teoría de la dependencia. Es decir, las limitaciones inherentes a ese prurito inveterado de explicar el desarrollo interno 
de cada formación social a partir de su articulación con otras formaciones sociales, en lugar de seguir el camino inverso.

Y es que la teoría de la dependencia ha hecho fortuna con un aserto que parece gozar de la caución de la evidencia, pero que merece ser repensado seriamente. Según dicha teoría, la indole de nuestras formaciones sociales estaría determinada en última instancia por su forma de articulación en el sistema capitalista mundial; cosa cierta en la medida en que se presenta como la simple expresión de otra proposición, ella sí irrefutable: el capitalismo, una vez que ya lo tenemos como dato de base, mal puede ser pensado de otra manera que como economía articulada a nivel mundial. Sólo que no todo ese razonamiento supone que dicho dato (el carácter capitalista de nuestras sociedades) es un dato teóricamente irreductible, que no puede ser concebido como producto permanente de una estructura interna que en cada instante lo está produciendo y reproduciendo. Cuando más, puede ser susceptible de una explicación genética (somos países dependientes porque siempre fuimos de una u otra manera dependientes), explicación que, por lo demás, nos encierra en un círculo vicioso en el que ni siquiera hay lugar para un análisis de las posibilidades objetivas de transformación de nuestras sociedades.

Por eso, la misma fórmula, aparentemente evidente, de la teoría de la dependencia, podría enunciarse de manera estrictamente inversa, para poner de relieve sus limitaciones y su unilateralidad: ¿no será más bien la índole de nuestras sociedades la que determina, en última instancia, su vinculación al sistema capitalista mundial?

En rigor, es esta segunda formulación la que está más cerca de la verdad. Si la revolución boliviana de 1952, por ejemplo, hubiera seguido un curso similar al de la Revolución Cubana, Bolivia no sería hoy un país dependiente: para serlo (y aquí no estamos hablando de situaciones coloniales o semicoloniales, sino de situaciones de dependencia en sentido restringido), hay que tener como premisa indispensable una estructura interna capitalista, o preñada de fuerzas históricas que tienden "naturalmente" hacia el capitalismo; de la misma manera que para avanzar al 
socialismo son necesarias fuerzas internas capaces de romper la estructura existente. Esto es indudable, pero no se trata aquí de colocarse "más cerca de la verdad" ni de reemplazar una visión adialéctica por otra similar, sino de recordar la doble perspectiva del problema.

Ningún error es gratuito, sin embargo. Si la teoría de la dependencia ha enfatizado unilateralmente un aspecto del problema, es debido a su empantanamiento en una problemática desarrolista, con su consiguiente perspectiva economicista no superada totalmente. Sólo así se comprende, además, que a partir de tal teoría no se haya producido un solo estudio sobre el desarrollo revolucionario cubano, ${ }^{38}$ caso omitido, incluso, en libros de un horizonte histórico tan amplio como Desarrollo y dependencia en América Latina.

La teoría de la dependencia no está desligada, sin embargo, de la Revolución Cubana y, sobre todo, de algunos de los efectos que ella produjo inicialmente en el resto del continente. ¿Cómo entender, si no, esta extraña mezcla de premisas nacionalistas y conclusiones socialistas, de una epistemología desarrollista y una ética revolucionaria que hemos venido analizando, si no es a partir de un hecho como la Revolución Cubana que, entre otras cosas, produjo una radicalización total de vastos sectores medios intelectuales, desgraciadamente desvinculados del movimiento proletario, tanto orgánica como teóricamente, y que, incluso, llegaron a ufanarse de su "independencia" frente a las organizaciones obreras, como en el caso del mismo Frank o del grupo de Monthly Review?

A partir de esta constatación, todo se torna en cambio coherente: el predominio omnímodo de la categoría dependencia sobre la categoría explotación, de la nación sobre la clase, ${ }^{39}$ y el mismo éxito fulgurante de la teoría de la dependencia en todos los sectores medios intelectuales. Incluso la ilusión de que con ello se

\footnotetext{
38 El libro de Vania Bambirra sobre la Revolución Cubana apareció con posterioridad a la redacción de este trabajo (nota de 1979).

39 Marini tiene el enorme mérito de ser la excepción en ambos casos.
} 
habían superado las "estrecheces" y "limitaciones" del marxismo clásico: ¿y cómo no iba a ser posible esta "superación” teórica, si en la misma práctica política las vanguardias de extracción intelectual creían poder reemplazar al proletariado en sus tareas revolucionarias?

Si esta hipótesis — seamos cautos- es cierta, el mismo movimiento crepuscular de la teoría de la dependencia hacia fines de la década de los sesenta podría explicarse por razones que irían más allá del simple desarrollo de las contradicciones de tal teoría. Tal vez no sean extraños a este itinerario acontecimientos como el "Cordobazo" argentino, la presencia de la clase obrera boliviana en el primer plano de la escena política de su país entre 1970 y 1971, o el ascenso de la Unidad Popular al gobierno en ese mismo momento; es decir, el repunte de las luchas proletarias en vastas zonas del continente.

Pero ¿ha muerto realmente la teoría de la dependencia? Más aún, ¿es algo que merezca ser enterrado? Ambiguo como siempre, Gunder Frank tituló uno de sus más recientes escritos: "La dependencia ha muerto, viva la dependencia y la lucha de clases". Ambiguo, decimos, puesto que no cabe confundir un hecho histórico objetivo con las teorías que a partir de él puedan elaborarse. La dependencia obviamente no ha muerto, ni nadie ha tratado en momento alguno de negar su existencia, ya que es una de las dimensiones más expresivas de nuestra realidad. Los estudios concretos que sobre ella se han hecho siguen y seguirán por lo tanto vigentes, y no como un simple reservorio de datos sino como una cantera inagotable de preocupaciones y sugestiones para la futura investigación. Lo que tal vez haya estallado sin remedio es esa caja de Pandora, de la que en un momento dado llegaron a desprenderse todas las significaciones e ilusiones, y que recibió el nombre de teoría de la dependencia. Caja de Pandora que, desde luego, no era un "lugar sin límites", sino un marco de representación de contornos definidos por la idea de que toda nuestra historia es deducible de las oposiciones "centro-periferia", "metrópoli-satélite" o "capitalismo clásico-capitalismo de- 
pendiente"; eje teórico omnímodo sobre el cual podían moverse desde los autores cepalinos hasta los neomarxistas.

Es este movimiento sociológico, cuya sociología queda aún por hacer, el que parece encontrarse ahora en franco declive o en vías de una positiva superación. Lo que empezó como una construcción barroca en Gunder Frank, tal vez termine, pues, con el edificio neoclásico de Marini, en el que se dibujan ya nuevas perspectivas. Para no mencionar la clara ruptura operada por Aníbal Quijano, por ejemplo, quien en uno de sus últimos trabajos ${ }^{40}$ no vacila en hablar de la teoría de la dependencia en pasado y retomar la línea general de análisis del marxismo-leninismo, recuperando, incluso, los aportes de uno de sus más grandes pensadores latinoamericanos, José Carlos Mariátegui.

40 Cfr. Aníbal Quijano, "Imperialismo, clases sociales y Estado en el Perú”, Seminario sobre Clases Sociales y Crisis Política en América Latina, Oaxaca, IIS-UNAM, junio de 1973. 